\title{
VALIDATION OF SPINAL SAGITTAL ALIGNMENT WITH PLAIN RADIOGRAPHS AND THE DEBRUNNER KYPHOMETER
}

\section{Corresponding author:}

Carl Todd MSc, DO. The Carl Todd Clinic, 5 Pickwick Park, Park Lane, Corsham, SN13 0HN, United Kingdom.

Email: carl.todd@me.com

Cecilia Agnvall, Carl Todd, Peter Kovac, Anna Swärd, Christer Johansson, Leif Swärd, Jòn Karlsson, Adad Baranto.

Department of Orthopaedics and Department of Radiology, Institute of Clinical Sciences at Sahlgrenska Academy University of Gothenburg and Sahlgrenska University Hospital, Gothenburg, Sportsmedicine Åre and Åre Ski High School, Sweden

\begin{abstract}
Validation of the Debrunner Kyphometer as a clinical non-radiological method for investigating spinal sagittal alignment was compared with standing lateral radiographs. The sample group $(n=102)$ consisted of elite Alpine skiers $(n=75)$ and a non-athletic population $(n=27)$, mean age $17.7( \pm 1.4)$ years. Non-radiological and radiological measurements of the spinal sagittal kyphosis and lordosis range of motion were carried out in the erect standing position. Thoracic kyphosis measurements comparing the Debrunner Kyphometer with a radiological standard, showed a good level of agreement and a statistical significance (ICC 0.67, 95\% CI:0.26 to 0.83, p<0.001). Lumbar lordosis measurements showed poor levels of agreement in spite of being statistically significant (ICC $0.33,95 \%$ CI: 0.13 to $0.50, \mathrm{p}=0.001)$. There was no significant difference reported in the spinal alignment between skiers and controls using both radiological and nonradiological methods. Therefore, we conclude that due to the large variation in ranges between both methods,there is a limited value in using the Debrunner Kyphometer as a non- invasive method for the evaluation of spinal sagittal alignment.

Key words: Debrunner Kyphometer, kyphosis, lordosis, radiological, spinal sagittal alignment
\end{abstract}




\subsection{Introduction}

Sagittal spinal balance is the integration of anatomical regions that provide shape, position, form and function between the spine, pelvis and hips (Berthonnaud,2005; Mac-Thiong et al., 2007). Such integration assists with spinal alignment and helps humans to maintain an upright posture, forward gaze and minimizes energy expenditure (Berthonnaud et al 2005; Descamps et al 1999; Duval-Beaupère et al1992; Rousouly \& Nnadi 2010). Spinal alignment is maintained regionally by the cranial and caudal lordotic curves that are separated by the kyphotic curve (Rousouly\& Nnadi 2010). Variations exist upon the degree of curvature, but essentially they allow for even force distribution throughout the spinal column (Boesker et al 2000; Bridwell \& Bernhardt 1989; Hardacker et al 1997; Roussouly et al 2005). Pathological or aging processes such as inflammatory or degenerative conditions may lead to progressive spinal malalignment and subsequent deformity (Rousouly \& Nnadi 2010).Radiographic evaluation of spinal sagittal alignment can be used in the assessment of local, regional and global spinal orientation (Mac-Thiong et al 2010). Such an evaluation provides objective information on many variables including the characteristics of the spinal curvatures, overall spinal alignment and malalignment, standing posture, progressive spinal deformities and pathological processes (Boesker et al 2000; Bridwell \& Bernhardt 1989; Hardacker et al 1997; Mac-Thiong et al 2010; Roussouly et al 2005; Roussouly \& Nnadi 2010; Roussouly \& PinheiroFranco, 2011). Radiographic evaluation unfortunately can be expensive, time consuming and risk an exposure to radiation, especially in young individuals; and therefore, exploring a non-radiological method to interpret results may provide an alternative option suitable for the clinical environment (Greendale et al 2011)

Clinical measurements of spinal curvatures and sagittal mobility using the Debrunner Kyphometer have been reported in many studies (Aaro \& Öhlén 1983; Debrunner 1972; Hellsing et al 1987; Lind-Johansson 1985; Salisbury \& Porter 1987; Öhlén et al 1988; Öhlén et al 1989). However, a recent systematic review by Barrett et al., (2014) showed inconsistent and conflicting levels of evidence with using such a non-radiological instrument. This suggests a knowledge gap and a need for further research on the validity of this clinical method.T he purpose of the present study is to (1) to validate the Debrunner Kyphometer as a clinical nonradiological method for investigating spinal sagittal alignment and to compare it with radiographs from both young elite skiers and a non- athletic population of a similar age. (2) To compare the sagittal spinal alignment between young elite skiers to that of a healthy nonathletic population of a similar age. Therefore, the hypothesis of the present study is to show (1) if The Debrunner Kyphometer is an effective measuring tool that can be used within the clinical environment, and if (2) Spinal sagittal alignment of young elite skiers is different to that of a healthy non-athletic population. To our knowledge this is the first study that will carry out such an investigation.

\subsection{Methods}




\section{Medical Research Archives}

The sample group $(n=102)$ consisted of young athletic elite alpine skiers $(n=75)$ and a non-athletic population $(n=27)$. Participants were recruitedand testing was carried out at an elite Ski School in Östersund, Sweden. Participants were excluded ifthey had an episode of low back, pelvic or hip pain and history of previous surgery to the lumbar spine, pelvis or hip joint or a history of systemic pathology including inflammatory arthritis or pelvic inflammatory disorders. Data collection encompassed clinical tests for standing spinal sagittal mobility and both frontal and lateral radiographs. These , Sweden (ID number: 692-13).

\subsection{Testing procedure}

2.1.1. The Dubrunner Kyphometer

A non-invasive measurement of spinal sagittal kyphosis and lordosis range of motion was carried out in the erect standing position (Figure $3 \& 4$ ) using the modified

Debrunner's

Kyphometer(Figure 1, Protek AG, Bern, Switzerland). The Debrunner Kyphometer is essentially a protractor with two arms that are placed on specific bony landmarks (Ensrud et al. 1997; Huang et al. 2006). The Debrunner Kyphometer is capable of providing measurement in a 1 degree-scale. The design measured

original Kyphometer

kyphosis angles up to $52^{\circ}$ (Debrunner,

1972). Each arm is connected by

large enough to a block, two spinous processes. Modifications increased the range to $70^{\circ}$ and made it suitable for measuring lumbar flexion and extension (Öhlén et al 1989). Participants were instructed to look straight-forward and stand relaxed, not "at attention" barefooted with heels together and arms werecalculated and reported in degrees. A blinded examiner marked anatomical landmarks and placed measuring instruments, therefore, maintaining consistency and avoiding inter-operator reliability. An assistant recorded all measurements, therefore, limiting investigation bias. Figure 2 provides an overview of the tests. The characteristics of the full sample are presented in Table 1. The present study was approved by the Regional Ethical Review Board in Gothenburg at The Sahlgrenska Academy, Gothenburg University, Gothenburg

hanging by their side (Öhlén et al 1988). The same examiner located and marked the bony landmark points by palpation. These were re-palpated and re-marked between each test due to skin drag from pelvic movement. In the present study intra and inter-observer reliability was tested measuring ten skiers with two examiners (One experienced physical therapist and one physician). Sagittal thoracic and lumbar spinal motion was measured separately. For the thoracic spine, marking ofthe anatomical landmarkswas by palpation between the T2-3 spinous processes and the lower point between T11-12 spinous processes. The upper measuring point was located by palpating below the $\mathrm{C} 7$ vertebrae andlower measuring point by tracing around the lower ribs to the T11-12 segments (Figure 3). In the lumbar spine anatomical landmarks were palpated and marked between T11-12 spinous processes and the lower point between the posterior superior iliac spine (PSIS) on the S1-2 segments (Figure 4). These were classified as the neutral 
position and measurements were recorded for kyphosis and lordosis.

\subsubsection{Plain radiographic examination}

For radiographic examinations, a standardized protocol was used for all participants (Mac-Thiong et al 2010). A frontal and long-standing lateral radiographswere obtained for each participant recorded from $\mathrm{C} 7$ to the femoral head. Participants were instructed to stand in a relaxed comfortable position with both hips and knees fully extended with arms horizontal resting on supports. The total measurement time was approximately 10 minutes. Automatic Exposure Control (AEC) was completed using a low dose and the edges of the images were enhanced toclearly distinguish vertebral bodies and endplates. Radiographic images were taken from the C7 vertebrae to the femoral head; these were overlapped and automatically stitched for ease of interpretation. To reduce radiation levels, the film focus distance (FFD)was increased to $120 \mathrm{~cm}$ (Brennan et al 2004). Frontal view with posterior- anterior (PA) beam direction, the entire vertebral bodies and half the femoral head were imaged. Lateral view with the beam direction from right to left, the entire vertebral bodies and half the femoral head were imaged. The entire vertebral bodies and the entire femoral head were imaged. The radiographs were measured for sagittal spinal alignment by a single blinded experienced radiologist with the angular parameters reported in degrees. A negative value (-) represented a lordotic alignment whilst a positive value $(+)$ represented a kyphotic alignment. Geometrical measurements relating to spinal curvatures were obtained from the following; thoracic kyphosis (TK)
(Figure 5) as the angle measured from the upper endplate of $\mathrm{T} 4$ to the lower endplate of T12. Lumbar lordosis (LL) (Figure 5) is defined as the angle measured from the upper endplate of L1 to the upper end-plate of $\mathrm{S} 1$.

\subsubsection{Statistical analysis}

Data was analysed using IBM SPSS Statistics for Windows, Version 22.0. Armonk, NY: IBM Corp. The description of data was expressed in terms of the mean and standard deviation (SD), median and range including frequencies and percentages where appropriate. Intraclass correlation coefficients (ICC) were calculated for both the Debrunner Kyphometer and the radiological method. The coefficients was interpreted according to Fleiss (1986) Benchmark Scale as Poor <0.40; Good 0.40 to 0.75 ; Excellent $>0.75$.Pearson correlation coefficients for thoracic kyphosis were calculated for both elite skiers and non-athletes. The statistical significance for all tests was set as $\mathrm{p}<0.05$.

\subsection{Results}

Table 1 summarises the demographic characteristics of the whole population. The mean age enrolled population was17.7 $( \pm 1.39)$ years. Due to drop-out and failure to attend investigations, only radiological data from 90participants and Debrunner Kyphometer data from 100 participants was available for analysis.Values and distribution of clinical and radiological measurements stratified by group are presented in Table 2. The skiers mean radiological thoracic kyphosis was $35.1^{\mathrm{O}}$ SD 7.4 and control group was $37.3^{\circ}$ SD 6.7. The skiers mean Debrunner Kyphometer thoracic kyphosis was $30.5^{\mathrm{O}}$ SD 6.5 and control 
group was $32.9^{\mathrm{O}}$ SD 6.4. The skiers mean radiological lumbar lordosis was $-58.4^{\mathrm{O}}, \mathrm{SD} 9.3$ and the control group was $-60.9^{\circ}$, SD 11.0. The skiers mean Debrunner Kyphometer lumbar lordosis was -27.2 SD 6.8 and the control group was -30.4 SD 7.3. Values for radiological and Debrunner Kyphometer comparisons for all participants and are presented in Table 3.The mean radiological thoracic kyphosis was $35.8^{\circ}$ SD 7.3, (range $12-52^{\circ}$ ). The meanvalue of the Debrunner Kyphometer thoracic kyphosis was $31.2^{\circ} \mathrm{SD} 6.6$, (range 15$49^{\circ}$ ). The mean radiological lumbar lordosis was $-59.1^{\circ} \mathrm{SD}-58$, (range -82 to$\left.38^{\circ}\right)$. The meanvalue of Debrunner Kyphometer lumbar lordosis was $-28.0^{\circ}$ SD 7.0, (range -44 to- $8^{\circ}$ ). Intraclass correlation coefficients (ICC) values for intra and inter operator reliability are presented in Table Debrunner Kyphometer comparisons for all participants and are presented in Table4. Excellent levels of intra- and inter-rater reliability were shown for thoracic kyphosis, compared with only good levels of intra and inter- rater reliability for lumbar lordosis. Intraclass correlation coefficient (ICC) values for validity of the Debrunner Kyphometer compared with radiology are presented in Table 5. Thoracic kyphosis comparison indicates a good level of agreement and a statistical significance between both measures (ICC 0.67, 95\% CI: 0.26 to $0.83, \mathrm{p}<0.001)$. Pearson's correlation coefficient $\quad(r=0.605$, $\mathrm{p}<0.001$ ) was calculated to measure the relationship between both variables (Figure 8).In contrast lumbar lordosis comparison between both methods indicates a poor level of agreement (ICC $0.33,95 \%$ CI: 0.13 to 0.50 , $\mathrm{p}=0.001)$. The difference in rangesfor measuring thoracic kyphosis (Figure 6)using Debrunner Kyphometer and a radiological method ranged from 7.7 to $-16.8^{\circ}$,whilst the differences in ranges for measuring lumbar lordosis (Figure 7) with the Debrunner Kyphometer and a radiological method ranged from 11.4 to $50.6^{\circ}$.

\subsection{Discussion}

The most important finding with this study, show that comparison of the Debrunner Kyphometer with a radiological standard is questionable due to the large variations and poor levels of agreement that exist between the methods. Therefore, we conclude there is limited value in using the Debrunner Kyphometer as a clinical method for the evaluation of spinal sagittal alignment. Moreover, no significant difference was reported in the spinal alignment between skiers and controls using both radiological and non-radiological methods.

In the present study mean values of thoracic kyphosis for both radiological $\left(35.8^{\circ}\right)$ and Debrunner Kyphometer $\left(31.2^{\circ}\right)$ appear similar to those previously reported within a normal asymptomatic population (Öhlén et al 1989; Korovessis et al 2001; Purser et al 1999; Greendale et al 2001; Willner 1981; Roussouly et al 2011). Mean values for radiological measurement of lumbar lordosis $\left(-59.1^{\circ}\right)$ in the present study also appear similar to those previously reported within a normal asymptomatic population (Boesker et al 2000; Bridwell \& Bernhardt 1989; Hardacker et al 1997; Voutinas \& MacEwen, 1986; Cil et al 2005; MacThiong et al 2007; Roussouly et al 2005; Roussouly \& Nnadi 2010; Roussouly \& Pinheiro-Franco, 2011; Roussoully et al 2011). However, mean values for the Debrunner Kyphometer measurement of lumbar lordosis $\left(-28.0^{\circ}\right)$ shows a lack of 
sensitivity and challenges the Debrunner Kyphometer as an effective clinical tool.

No significant differences were noted for comparison of stratified groups, i.e. skiers versus controls. This was similar with using both methods. Radiological values for thoracic kyphosis of skiers $\left(35.2^{\circ}\right)$ and controls $\left(37.4^{\circ}\right)$ compared with lumbar lordosis of skiers $\left(-58.4^{\circ}\right)$ and controls ($60.9^{\circ}$ ), appeared similar to the Debrunner Kyphometer values for thoracic kyphosis of skiers $\left(30.5^{\circ}\right)$ and controls $\left(32.9^{\circ}\right)$ compared with lordosis of skiers $\left(-27.2^{\circ}\right)$ and controls $\left(-30.4^{\circ}\right)$. This may suggest early participation in sport does not affect sagittal spinal alignment within a young population. In the present study, measurements were recorded in the erect standing and sagittal plane only. However, this does not reflect the multidirectional dynamic movement patterns required to perform sporting activities.

Previous studies report strong reliability using the Debrunner Kyphometer(Öhlén et al 1988; Öhlén et al 1989; Salisbury \& Porter 1987; Korovessis et al 2001; Purser et al 1999; Greendale et al 2001). This was similar to the present study,where reliability of the Debrunner Kyphometer showed excellent levels for both intra-tester (ICC 0.83) and intertester (ICC 0.96) measurement of thoracic kyphosis and good levels in terms of intra-tester (ICC 0.71) and intertester (ICC 0.79) reliability for measuring lumbar lordosis.A recent systematic review by Barrett et al. (2014) included only two studies that were classified as suitable for inclusion to investigate the validity of the Debrunner Kyphometer. Although Greendale et al. (2011) and Korovessis et al. (2001) both showed moderate to high levels of validity, inadequacies exist within the methodologies and statistical analysis of their studies (Barrett et al 2014). In the present study validity of the Debrunner Kyphometer with radiology showed a good level of agreement between both measures (ICC 0.67) for thoracic kyphosis. However, poor levels of agreement (ICC 0.33) were shown between both measures for lumbar lordosis. Due to the large variation in range of theICC value, the Debrunner Kyphometer is therefore, shown to have a limited clinical value.

Greendale et al. (2011)created a predictive formula to measure nonradiological kyphosis. Such a prediction highlights problems, as the correlation coefficient does not measure the agreement between two methods but is a standardized measure of the strength of the relationship. Korovessis et al. (2001) used both linear and multiple regression analysis to correlate values and construct a predictive formula for measuring kyphosis. Establishing a calibration using linear regression between the Debrunner Kyphometer and the radiographic angle is questionable, due to the large variations that appear to exist between the two methods.In the present studythe limits of agreement for thoracic kyphosis ranged from $8^{\circ}$ to $-17^{\circ}$. Therefore a possibility exists that the Debrunner Kyphometer could show a reading as high as $8^{\circ}$ above or $17^{\circ}$ below that of a radiological investigation. Moreover, the limits of agreement for lumbar lordosis ranged from 11 to $51^{\circ}$ implying the Debrunner Kyphometer could show a reading as high as $11^{\circ}$ above or $51^{\circ}$ below that of a radiological method. Such a large variation between both methods questions the Debrunner Kyphometer's validity and appears similar to what has been reported 
in other studies (Greendale et al 2011; Korovessis et al 2001; Barrett et al 2014).

There are somelimitations to this study. These include, participant positioning and instructions (Korovessis et al 2011), location and accuracy of palpation, errors in clinical measurement(Mannion et al 2004;O'Haire \& Gibbons, 2000; French et al 2003; Bills et al 2003), and fatigue from repeated measuring(Hinman 2004; van Blommestein et al 2012; Sheeran et al 2010). Other limitations may relate to positioning the Debrunner Kyphometer on the spine. The Debrunner Kyphometer is positioned on the spinous processes as radiographic investigations measure from the vertebral bodies (Mannion et al 2004). In the present studyDebrunner Kyphometer measurements were taken by poisitioning the instrument on the relevant spinous processes or bony landmarks. Radiographic measurements were calculated from standing lateral radiographs using the relevant upper and lower vertebral end plates (Cobb, 1948; Singer et al 1994; Harrison et al 2002; Roussouly \& Nnadi 2010).

In the present study a well-documented "relaxed standing method" suggested by Öhlén et al (1988) was used. This was similar to Greendale et al. (2011) but differed from Korovessis et al (2011) who chose the "erect standing method" as suggested by Stagnara et al. (1982). Such a difference in terminology may increase the variability between clinical and radiological measurements (Korovessis et al 2011).Location and accuracy of specific anatomical bony landmark palpation may also be variable due to the distribution of adipose tissue overlying the spinal structures (Mannion et al 2004). One validated study using external devices for spinal measurement, highlighted good reliability with a Body Mass Index (BMI) $<25$ (Ripani et al 2008). In the present study, participants were young elite skiers and non-athletes of a similar age. Collectively their total body mass index (BMI) was calculated as mean 22.9. Therefore, such a low BMI distribution may have allowedfor ease of palpation of specific anatomical bony landmarks.Age and health can play a significant role in sagittal spinal alignment. The mean age of the sample in the present study was 17.7 similar to that of a previous study by Korovesis et al (2001). Having such a young sample in the present study possibly highlights the lack of excessive sagittal plane curvatures noted. Moreover, ahealthy population was selected in the present study however; this may have limitedthe ability to distinguish alignment from malalignment using this clinical method.

The Debrunner Kyphometer was originally designed to measure thoracic kyphosis, modifications increased its ability to evaluate lumbar flexion and extension (Öhlén et al 1989). Perhaps by increasing such a range, the Debrunner Kyphometer becomes more susceptible to errors in clinical judgement. This might also explain why the majority of published studies investigating the Debrunner Kyphometer report predominantly on measuring thoracic kyphosis (Öhlén et al 1989; Korovessis et al 2001; Purser et al 1999; Greendale et al. 2001). Therefore, although in the present study the Debrunner Kyphometer showed good validity for thoracic kyphosis, only poor levels of validity were shown for lumbar lordosis. Therefore the present study can refute our hypothesis that the Debrunner Kyphometer can be used as an effective clinical method for measuring spinal alignment. 


\subsection{Conclusion}

The validity of the Debrunner Kyphometer as an appropriate clinical method for measuring spinal angles is questionable. This is due to the lack of sensitivity and the large range of variations that exist when correlating such a non-radiological method with a radiological standard. Therefore we conclude that due to the lack of clinical interpretation, there is limited value in using the Debrunner Kyphometer as a clinical method for evaluation of spinal sagittal alignment.

\subsection{Acknowledgement}

The authors acknowledge the financial support of The Medical Society of Gothenburg, Sweden, Governmental grants under the ALF agreement, Handlanden Hjalmar Svenssons Research Foundation and Doktor Felix Neuberghs Foundation, Carl Benett AB, Swedish National Centre for Research in Sports. The authors would also like to thanks Dr Flemming Pedersen and Dr Zaid Obady at Dep of Radiology Östersunds Hospital, Sweden for their help with the radiological examination and Christer Johansson, OrigoVerus AB, Gothenburg, Sweden for statistical assistance. 


\section{REFERENCES}

Aaro S \& Öhlén G. (1983).

The effect of Harrington instrumentation on the sagittal configuration and mobility of the spine in scoliosis. Spine, 8:570-575.

Barrett E., McCreesh K., Lewis J. (2014). Reliability and validity of non- radiographic methods of thoracic kyphosis measurement:

A systematic review. Manual Therapy. 19:10-17

Berthonnaud E, Dimner J, Roussouly P, Labelle H. (2005). Analysis of the sagittal balance of the spine and pelvis using shape and orientation parameters. $J$ Spine Disord, 18(1):40-47.

Billis EV, Foster NE, Wright CC. (2003). Reproducibility and repeatability: errors of three groups of physiotherapists in locating spinal levels by palpation. Man Ther. 8(4):223e32.
Boesker, E., Moe, J., Winter, R., Koop, S. (2000). A determination

of the normal thoracic kyphosis: a roentgengraphic study of 121 normal children. $J$ Pediatr Orthop, 20:796798.

Brennan, P., McDonnell, S., O'Leary, D. (2004). Increasing filmfocus distance (FFD) reduces radiation dose for x-ray examinations. Radiat Prot Dosimetry. 108(3):263-8.

Bridwell, K., Bernhardt, M. (1989). Segmental analysis of the sagittal plane alignment of the normal thoracic and lumbar spines and thoracolumbar junction. Spine, 14:717721. 
Cobb JR.(1948). Outline for the study of scoliosis. Instr Course Lect 5:261-268.

Cil A, Yazici M, Uzumcugil A, Kandemir Acaroglu R, Surat A. (2005). The evolution of sagittal segmental alignment of the spine during childhood. Spine, 30:93-100.

Debrunner H. (1972). das Kyphometer. Z Orthop, 110:389-392.

Descamps, H., Commare, M., Marty, C., Hecquet, J., Duval-Beaupere, G. (1999). Modifications des angles pelviens, don't l'Incidence pelvinne, au cours de

la croissance humaine. Biom Hum et Anthropol, 17:59-63. U, Alanay A, Alanay $\mathrm{Y}$,

(1992). A Barycentremetric study of sagittal shape and pelvis: the conditions required for an economic standing position. ANN Biomed Eng, 20:451462.

Ensrud KE, Black DM, Harris F et al. (1997). Correlates of kyphosis in older women. J Am Geriatr Soc, 45:682-687.

Fleiss J. (1986).The Design and Analysis of Clinical Experiments. New York: John Wiley \& Sons.

French SD, Green S, Forbes A. (2000). Reliability of chiropractic methods commonly used to detect manipulable lesions in patients with chronic low-back pain. $J$ Manipulative Physiol Ther, 23(4):231e8.

Duval-Beaupere, G., Greendale, G., Nili, N., Schmidt, C., Cosson, P.
Huang, M., Seeger, L., 
Karlamangla, A. (2011).

The reliability and validity of three non-radiological measures of thoracic kyphosis and their relations to the standing radiological Cobb angle. Osteoporosis Int, 22:1897-1905.

Hardacker, J., Shuford, R., Capicotto, R., Pryor, P. (1997). Radiographic standing cervical segmental alignment in adult volunteers without neck problems. Spine, 22:14721480.

Harrison DE, Cailliet $\mathrm{R}$, Harrison DD et al (2002). Reliability of Centroid, Cobb and Harrison posterior tangent methods: which to choose for analysis of thoracic kyphosis. Spine, 26:E227E234.
Hellsing E, Reigo T, McWilliam J, Spangfort E. (1987). Cervical and lumbar lordosis and kyphosis in 8, 11 and 15year-old children. Eur $J$ Orthod, 9:129-138.

Hinman MR. (2004). Interrater reliability of flexicurve postural measures among novice users. J Back Musculoskelet Rehabil, 17(1):33.

Huang MH, BarrettConnor E, Greendale GA et al. (2006). Hyperkyphotic posture and risk of future osteoporotic fractures: the Rancho Bernardo study. $J$ Bone Miner Res, 21(3):419-423.

Korovessis P, Petsinis G, Papazisis Z, Baikousis A. (2001). Prediction of thoracic kyphosis using the Debrunner kyphometer. $J$ Spinal Disord, 14(1):67e72. 


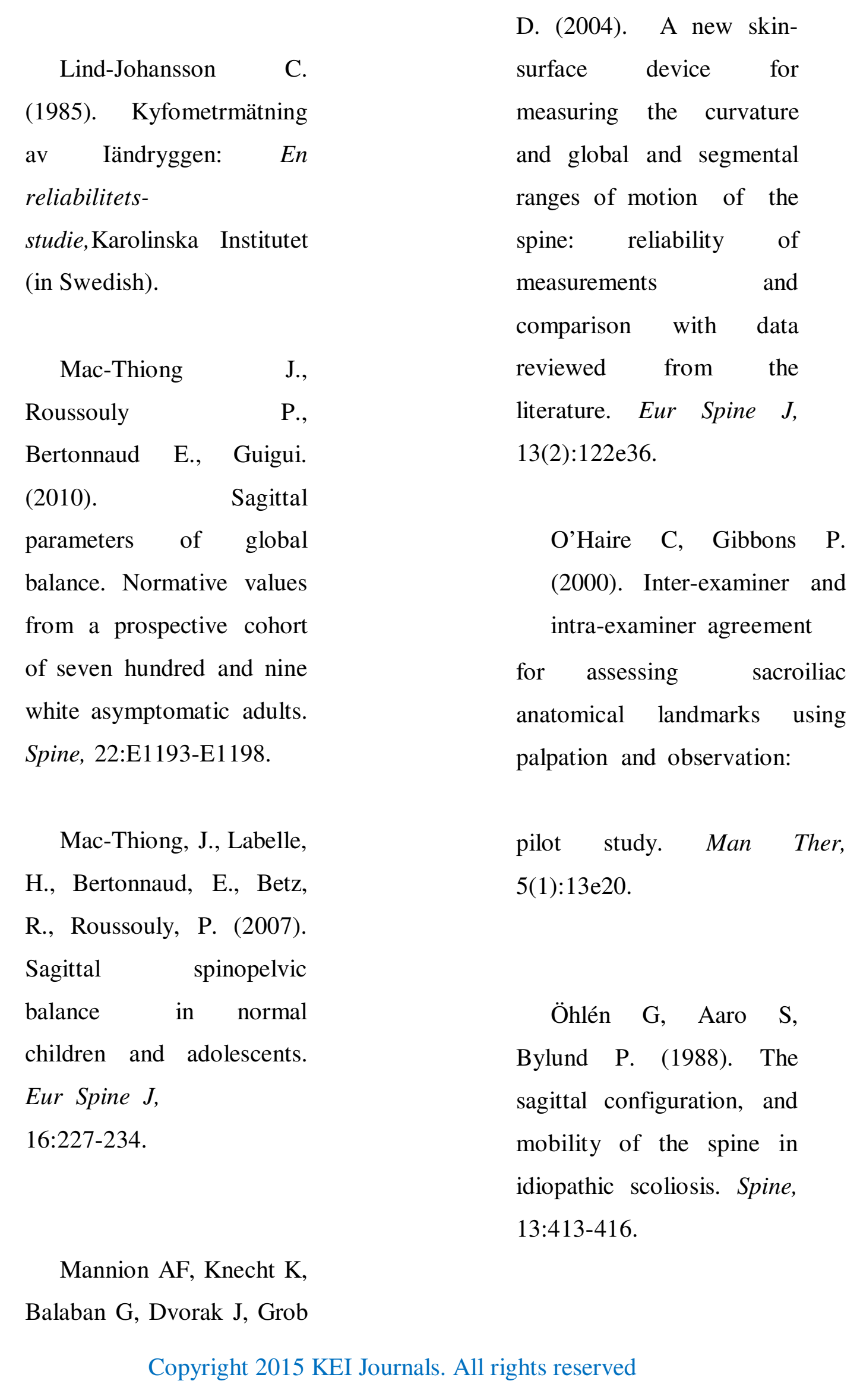


Öhlén G, Spangfort E,

Tingvall C. (1989).

Measurement of spinal

configuration and mobility

with Debrunner's

kyphometer. Spine, 14:580-

583.

Öhlén G, Wrednark T, Spangfort E. (1989). Spinal sagittal configuration and mobility related to Lowback pain in the female gymnast. Spine, 8:847-850.

Purser JL, Pieper CF, Branch LG, Duncan PW, Gold DT, McConnell ES, et al. (1999). Reliability of physical performance tests in four different randomized clinical trials. Arch Phys Med Rehabil, 80:557e61.

Roussouly, P., Pinheiro-Franco, J. (2011). Biomechanical analysis of the spino-pelvic organization and adaptation in pathology.

Eur Spine J, 20 (Suppl

5):S609-S618.

Roussouly P., Nnadi C. (2010). Sagittal plane deformity: an overview of interpretation and management. Eur Spine J, 19:1824-1836.

Roussouly, P., Gollogly, S., Bertonnaud, E., Dimnet, J. (2005). Classification of the normal variation in the sagittal alignment of the human lumbar spine and pelvis in the standing position. Spine, 30(3):346-353.

Ripani M, Di Cesare A, Giombini A, Agnello L, Fagnani F, Pigozzi F. (2008). Spinal curvature: comparison of frontal measurements with the spinal mouse and radiographic assessment. $J$ 
Sports Med Phys Fitness, 48(4): 488e94.

Salisbury PJ, Porter RW. (1987). Measurement of lumbar sagittal mobility. A comparison of methods. Spine, 12:190-193.

Sheeran L, Sparkes V, Busse M, van Deursen R. (2010). Preliminary study: reliability of the spinal wheel. A novel device to measure spinal postures applied to sitting and standing. Eur Spine J, 19(6):995e1003.

Singer $\mathrm{KP}$, Edmondston SJ, Day RE et al. (1994). Computerassisted curvature assessment and Cobb angle determination of the thoracic kyphosis. Spine, 19:1381-1384.
Stagnara, P., De Mauroy, J., Dran, G., Gonon, G., Costanzo, G., Dimnet, J., Pasquet, A. (1982). Reciprocal angulation of vertebral bodies in a sagittal plane: approach to references for the evaluation of kyphosis and lordosis. Spine, (Phila Pa 1976) 7(4):335-342.

Van $r$ Blommestein
AS, Lewis $\quad$ AS,
Morrissey MC, MacRae
S. (2009). Reliability of
measuring thoracic
kyphosis angle, lumbar
lordosis angle and straight
leg raise with an
inclinometer. Open Spine J,
4:10e5.
Voutsinas S, MacEwen G. (1986). Sagittal profiles of the spine. Clin Orthop,

210:235-242. 
VALIDATION OF SPINAL ALIGNMENT WITH RADIOGRAPHS \& KYPHOMETER

Medical Research Archives

Willner S. (1981).

Spinal pantograph: a non-

invasive technique for

describing kyphosis and

lordosis in the thoraco-

lumbar spine. Acta Orthop

Scand, $\quad 52: 525 \mathrm{e} 9$. 
VALIDATION OF SPINAL ALIGNMENT WITH RADIOGRAPHS \& KYPHOMETER

Medical Research Archives 
VALIDATION OF SPINAL ALIGNMENT WITH RADIOGRAPHS \& KYPHOMETER

Medical Research Archives

Table 1. Baseline characteristics for all subjects and stratified by group

\begin{tabular}{llll}
\hline & All subjects $(\boldsymbol{n = 1 0 2})$ & Skiers $(\boldsymbol{n}=\mathbf{7 5})$ & Controls $(\boldsymbol{n}=\mathbf{2 7})$ \\
\hline Age (years) & $17.7(1.39)$ & $18.3(1.13)$ & $16.4(0.57)$ \\
Female sex, $\mathrm{n}(\%)$ & $35(47 \%)$ & $18(67 \%)$ \\
Height $(\mathrm{cm})$ & $173(8.33)$ & $174(8.19)$ & $172(8.56)$ \\
Weight $(\mathrm{kg})$ & $69(12.16)$ & $70(9.14)$ & $67(17.91)$ \\
Body mass index $\left(\mathrm{kg} / \mathrm{m}^{2}\right)$ & $22.9(3.27)$ & $22.9(2.12)$ & $22.7(5.25)$ \\
\hline
\end{tabular}

Values are mean and (standard deviation) unless specified otherwise

Table 2: Measurements stratified by group mean and standard deviation

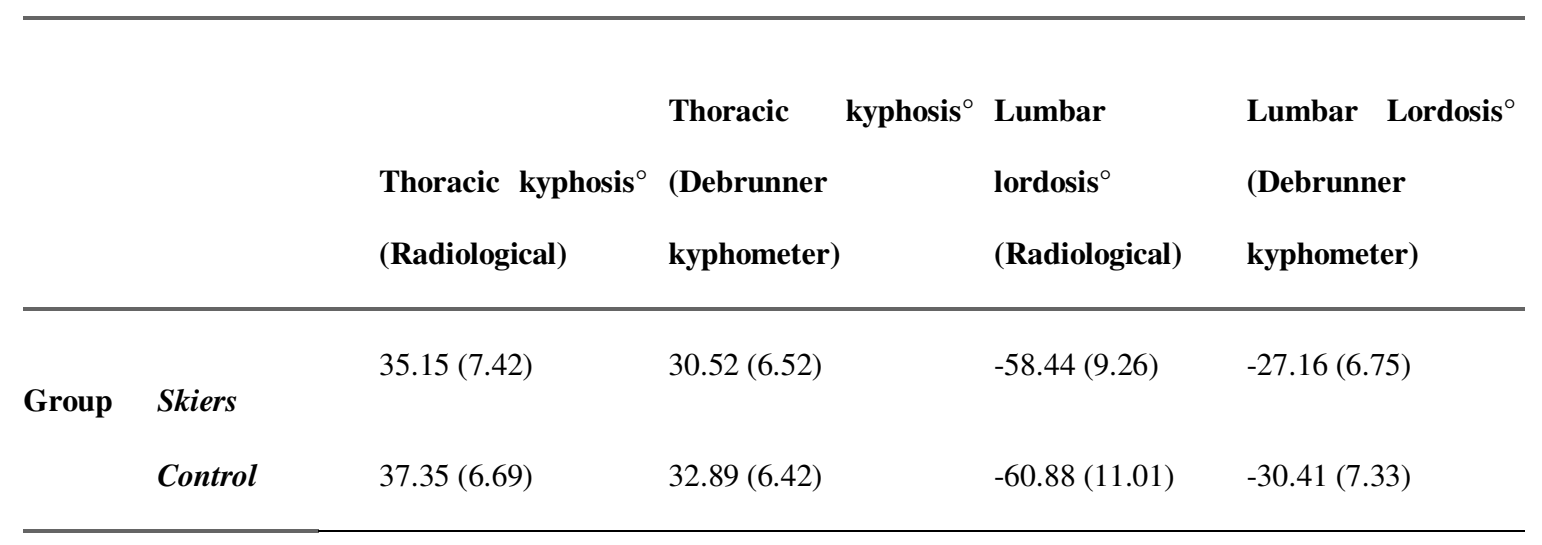

Mean (standard deviation) 
VALIDATION OF SPINAL ALIGNMENT WITH RADIOGRAPHS \& KYPHOMETER

Medical Research Archives

\section{Table 3:}

All subjects: Kyphosis and lordosis by radiological and non-radiological measures

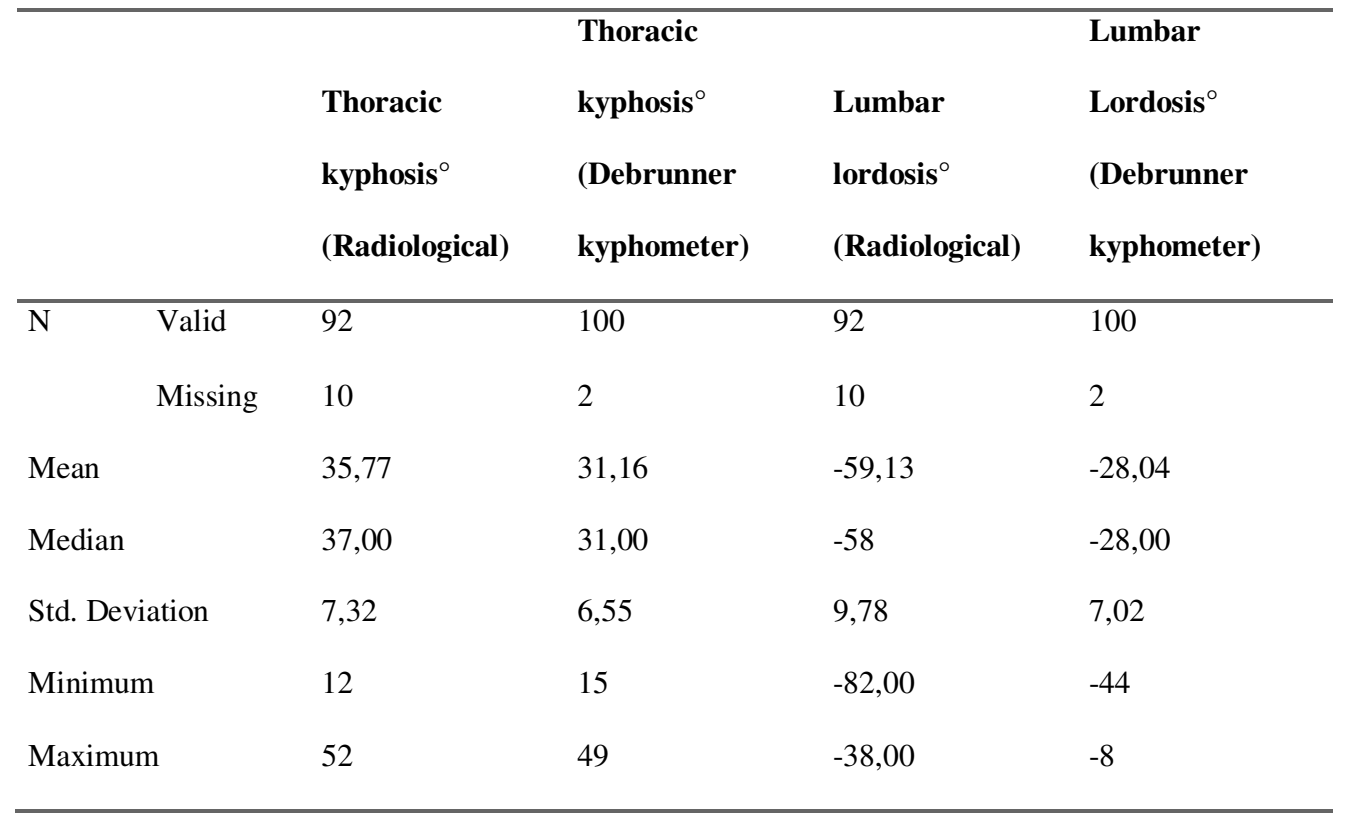

Table 4: Reliability of the Debrunner Kyphometer compared to the radiological measurements

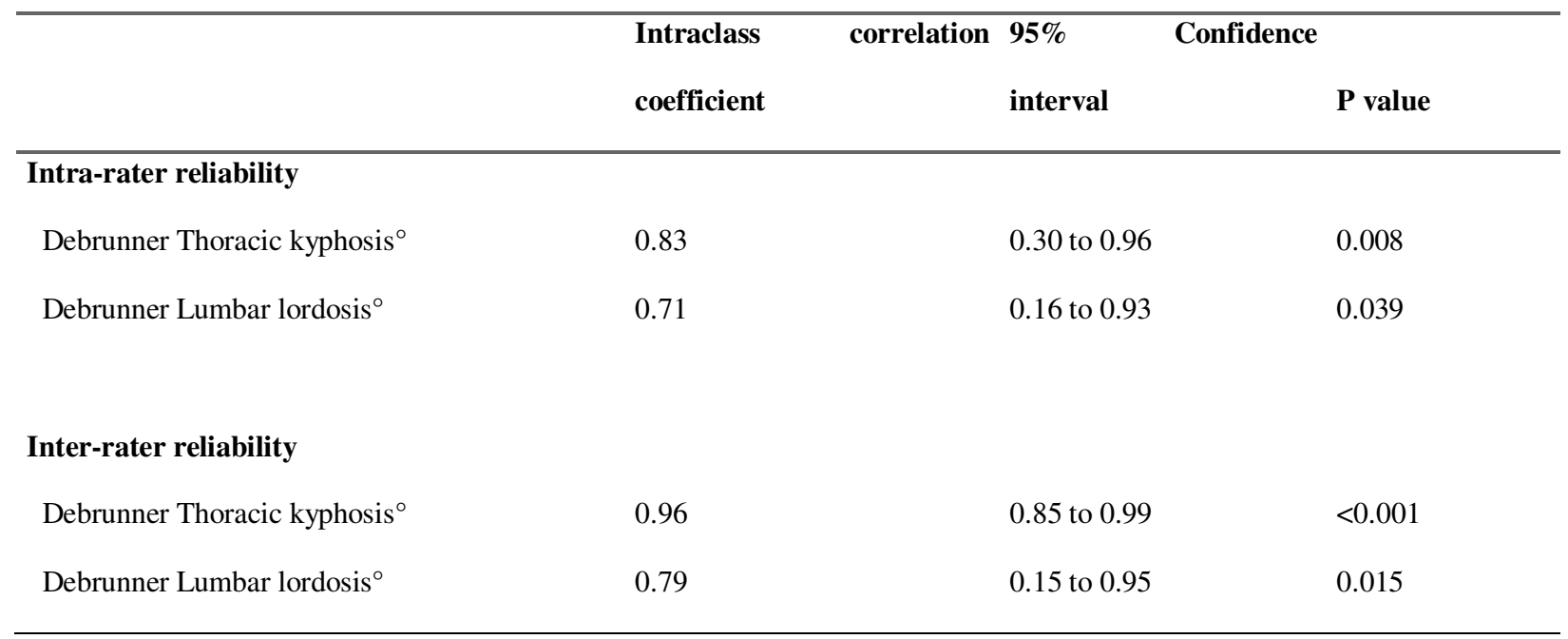

Table 5: Validity of the Debrunner kyphometer compared to the radiological measurements

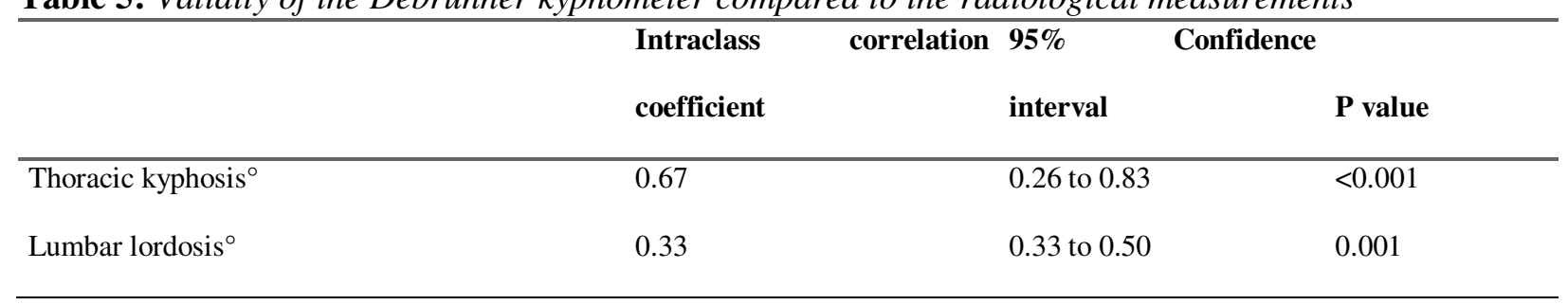


VALIDATION OF SPINAL ALIGNMENT WITH RADIOGRAPHS \& KYPHOMETER Medical Research Archives

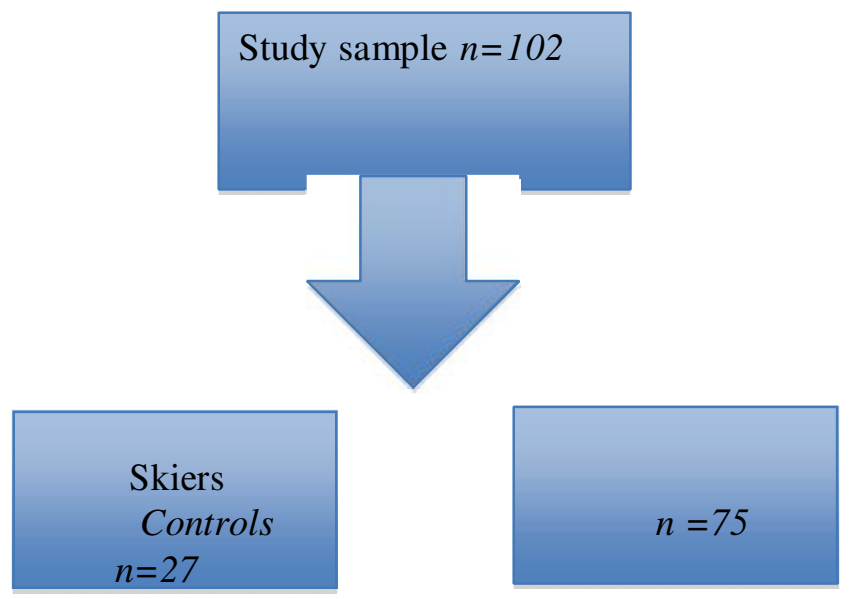


VALIDATION OF SPINAL ALIGNMENT WITH RADIOGRAPHS \& KYPHOMETER Medical Research Archives
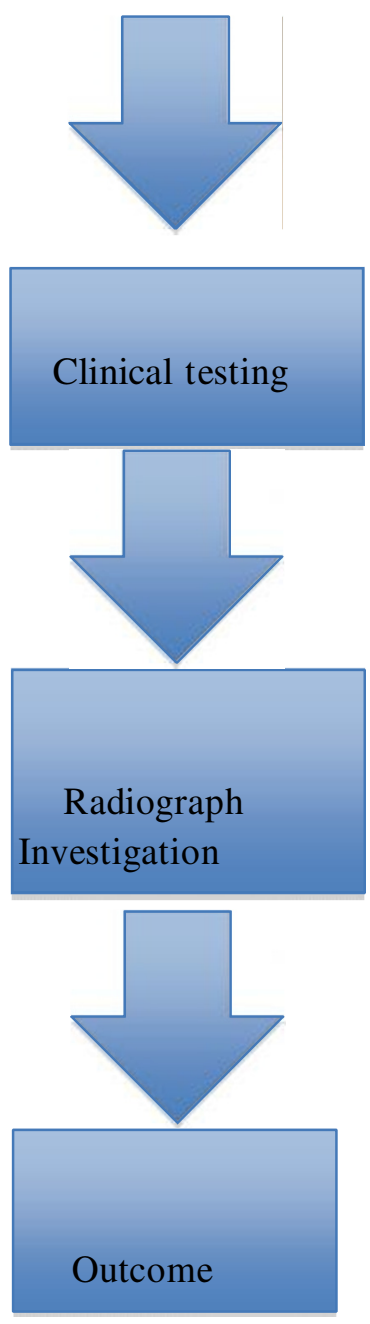

Figure 1:Algorithm of study methodology
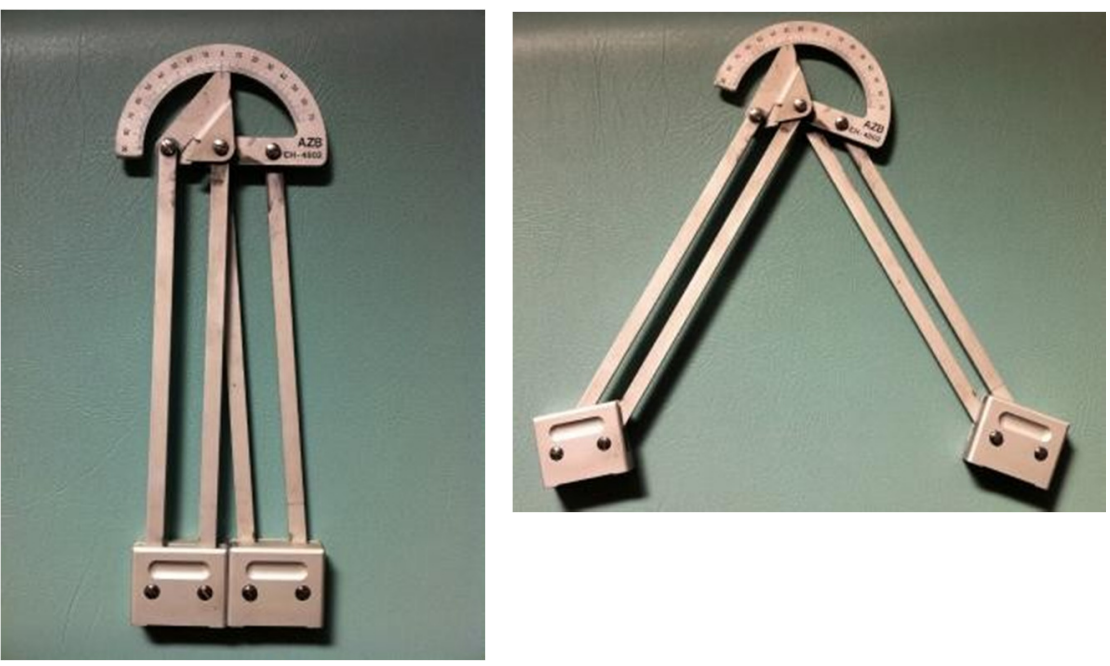
VALIDATION OF SPINAL ALIGNMENT WITH RADIOGRAPHS \& KYPHOMETER Medical Research Archives

Figure2. Modified Debrunner Kyphometer closed and open position 


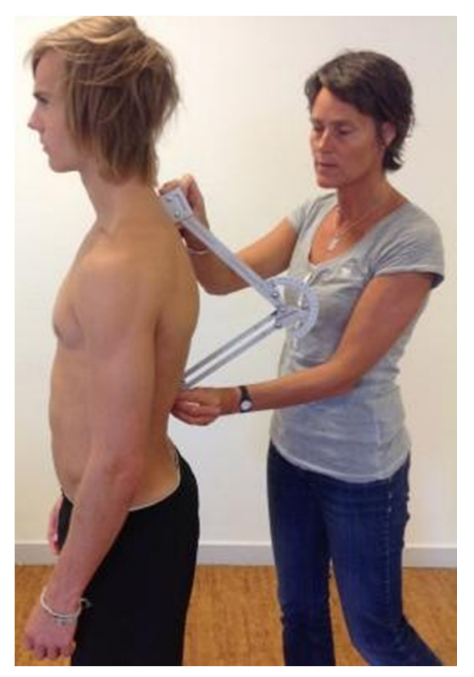

Figure 3: Position for measuring thoracic kyphosis
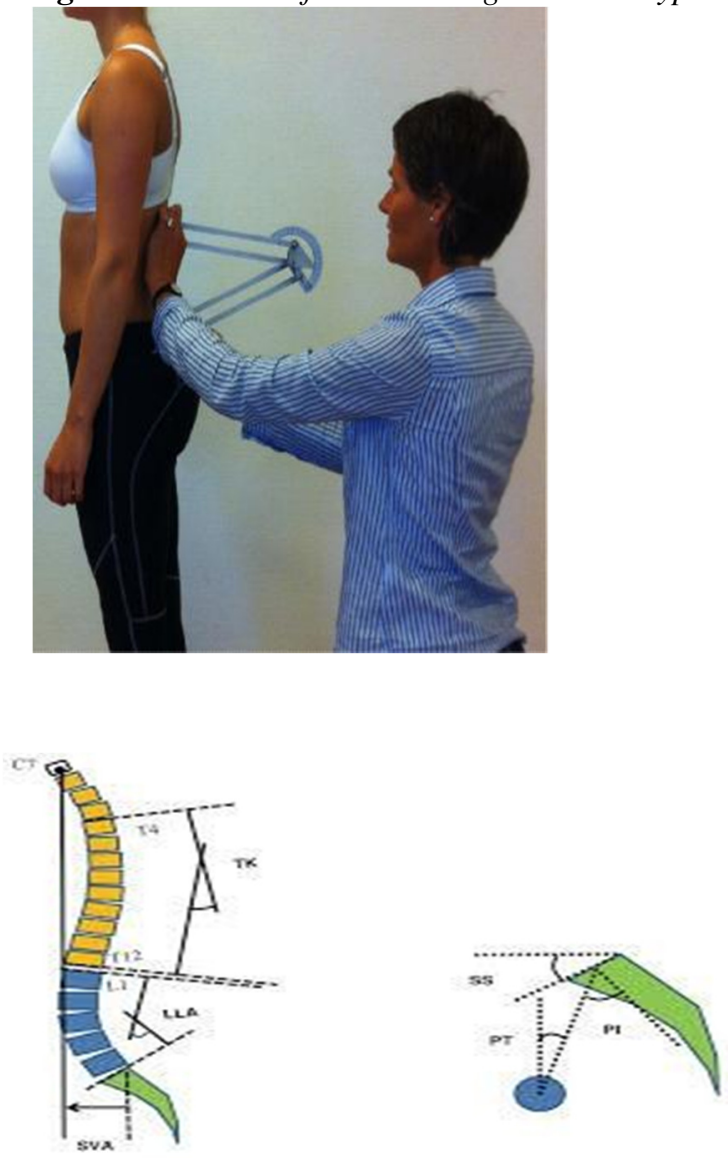

Figure 4:Position for measuring lumbar lordosis 
Figure 5:

Showing spinal angles

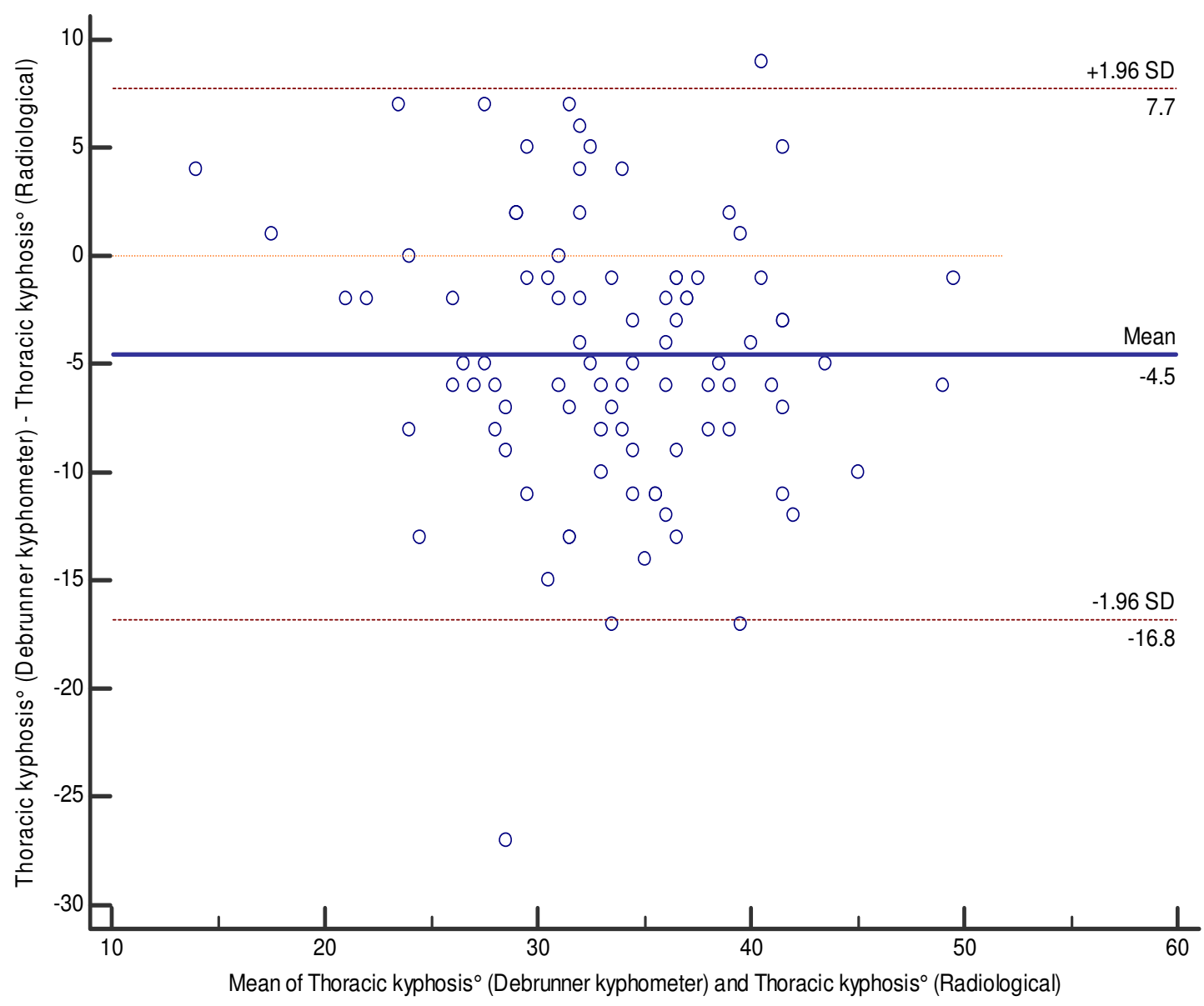

Figure 6:

Bland Altman plot highlighting ranges for thoracic kyphosis between Radiological and

Debrunner

Kyphometer 
VALIDATION OF SPINAL ALIGNMENT WITH RADIOGRAPHS \& KYPHOMETER

Medical Research Archives

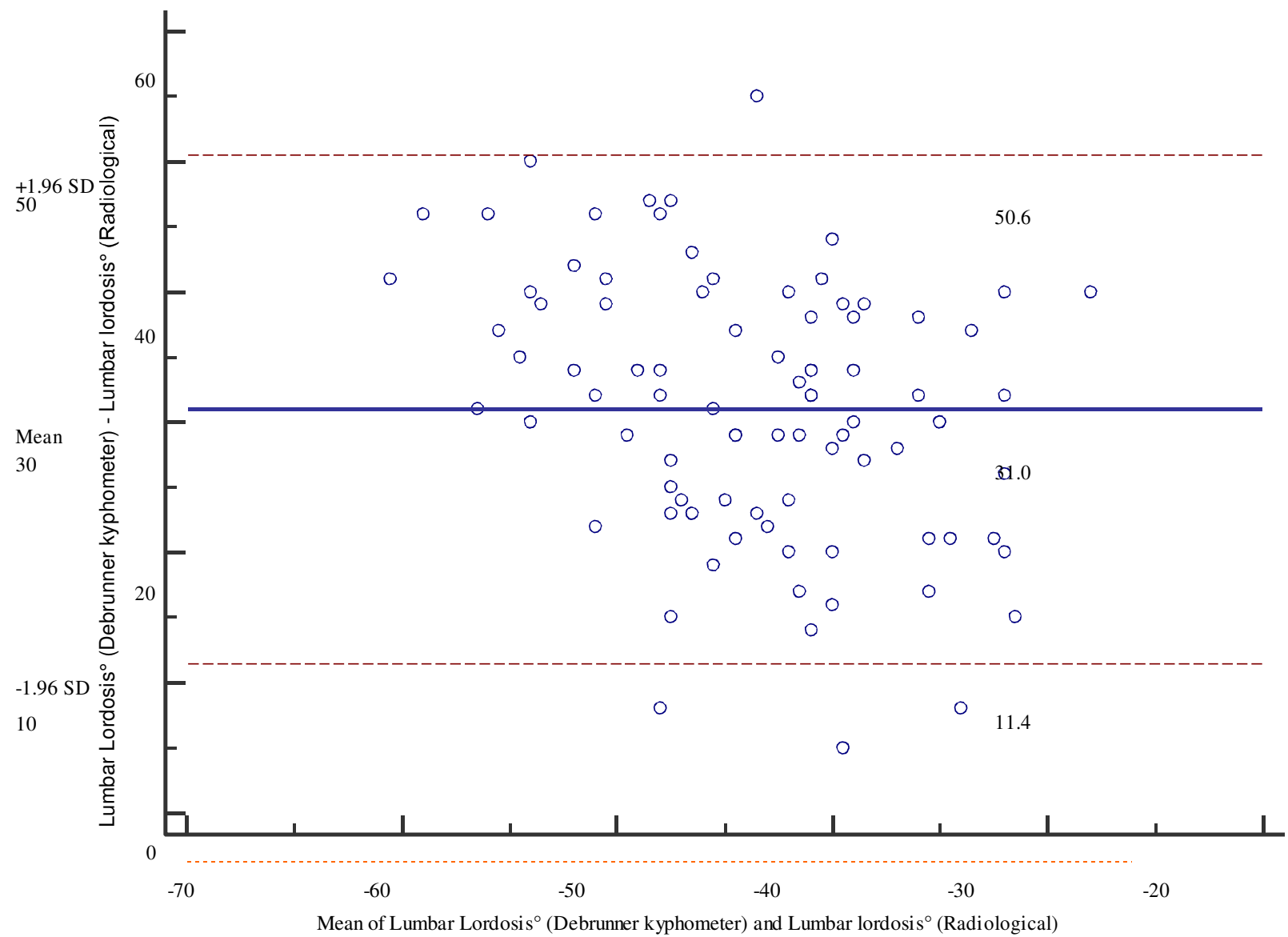

Figure 7:

Bland Altman plot highlighting ranges for lumbar lordosis between Radiological and 


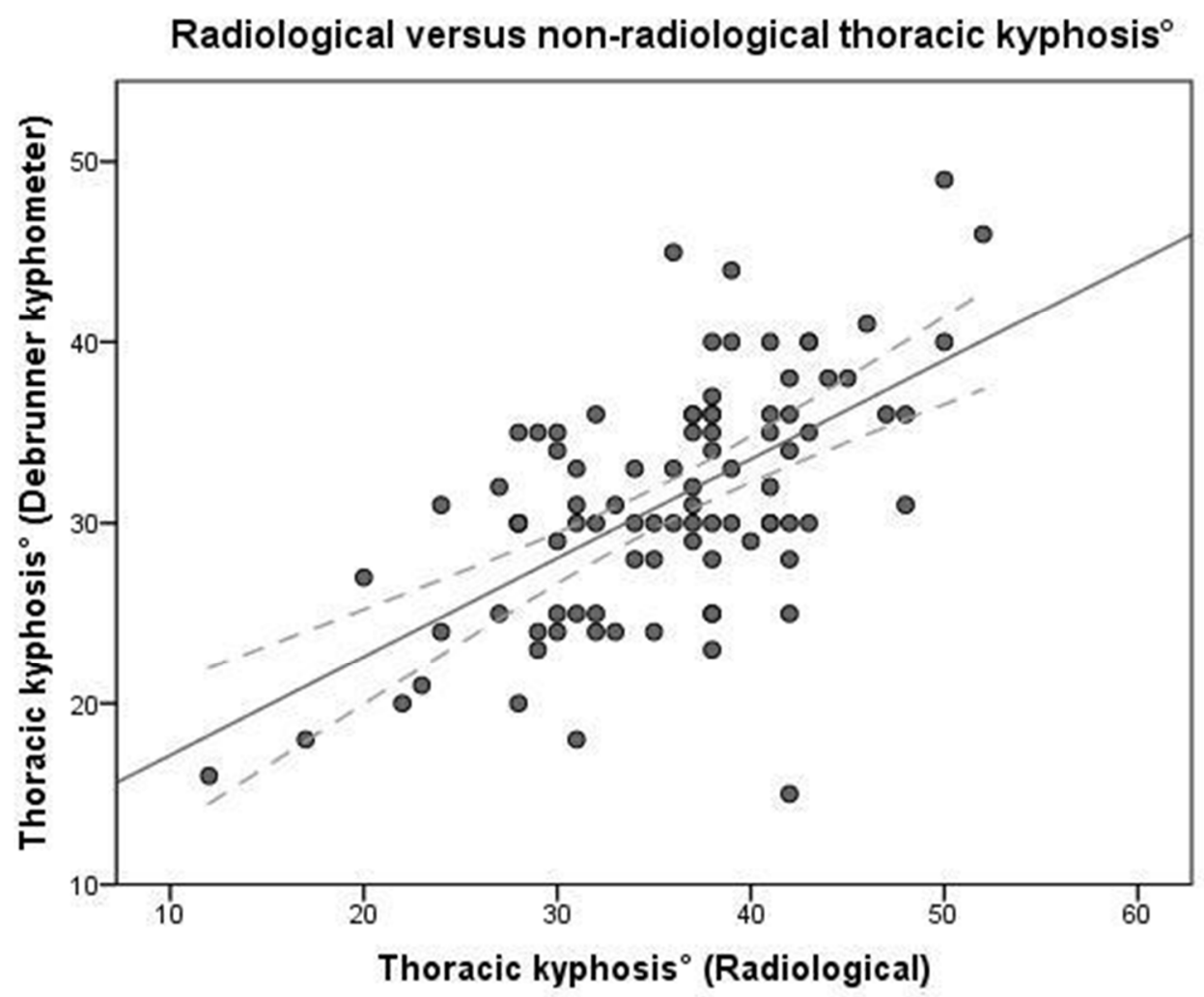

Figure 8:

Showing correlation between the measured Cobb angle and the measured Debrunner kyphometer (Pearson's $r=0.605, P<0.001)$. 